\title{
REVIEWS
}

\section{INTERACTIVE GOVERNANCE: ADVANCING THE PARADIGM}

\section{Jacob Torfing, B. Guy Peters, Jon Pierre and Eva Sørensen}

Oxford University Press, 2012, 280 pp., \$85 (hb), ISBN: 9780199596751

Every so often a book comes along that catches and consolidates fundamental shifts in the practice or breakthroughs in the study of public administration. Simon's Administrative Behavior was one, as were Downs' Inside Bureaucracy, Selznick's Leadership in Administration, Pressman and Wildavsky's Implementation, March and Olsen's Rediscovering Institutions, Ostrom's Governing the Commons, and Rhodes' Understanding Governance. My hunch is that Interactive Governance could be such a book; it is at least my belief that it should be. Two well-known writing duos (Peters and Pierre, Torfing and Sørensen) combine their diverse and formidable intellectual powers to produce a thought-provoking synthetic, programmatic, and fundamental theoretical account of a new frontier in governance.

The book addresses a range of practices that have been bubbling for years, but more recently have proliferated in countries and policy sectors throughout the world: openended, fluid, complex, forms of multiparty social problem-solving that are not dominated by state actors nor confined to more conventional policy networks. Think of: emergent information-sharing and coordination networks; efforts to produce holistic solutions for complex clients in public service delivery; self-steering community improvement initiatives; social entrepreneurs engaging with governments and business to create and disperse public value production that 'makes a buck' at the same time; social compacts between governments and not-for-profit sectors; or place-based public-private partnerships and economic development consortiums.

Torfing et al. have coined the term 'interactive governance' for all such joint efforts to address public issues or produce (more, smarter) public value. They define it formally as 'the complex process through which a plurality of actors with diverging interests interact in order to formulate, promote and achieve common objectives by means of mobilizing, exchanging and deploying a range of ideas, rules and resources' (p. 14). Quite a mouthful, indeed. But in the pages that follow, the authors do a tremendous job, in much crisper language, of clarifying the essential nature of this cluster of phenomena. They explain how it differs from 'government' and much of the 'governance' as we have come to know it, and why it has come about. Most of all they tell us how we should think about, empirically observe (they even talk about 'measuring'), as well as interpret and evaluate it.

The authors distinguish between three basic types of interactive governance: quasimarkets, partnerships, and networks. Each, they argue, is characterized by three key features: they are complex and process-based rather than linear and grounded in existing institutions; they are about the articulation and pursuit of common objectives in the face of divergent interests and preferences; and they are fundamentally decentred in that 'no

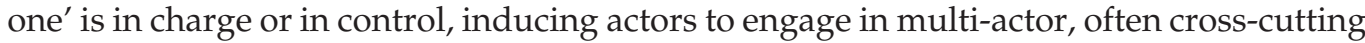
conversations and negotiations. It is only when these can be channelled in productive ways that things start to happen on the ground. Miscommunication, exclusion of salient 
voices, and paralytic stalemates are ever-present threats to this type of governance. The book helps us understand when and why this might be the case, and how it might be overcome.

The subtitle of the book might give the impression that the book is written in praise of these new practices. Yet what the authors seek to advance first and foremost is not a set of practical tools for governance but sustained academic attention on what they plausibly argue is a robust and growing phenomenon. They advance a multi-faceted, systematic, and self-consciously critical approach to analysing that phenomenon.

In the first two chapters they contextualize interactive governance as a trend and an object of study not just within the field of public administration but in a wide range of social science disciplines. Then follows a chapter that deals with the oft-neglected question of power in governance. They politely but firmly criticize some of their most illustrious predecessors, including March and Olsen, for this shortcoming. In the power chapter, they revisit Lukes' and Foucault's pivotal contributions (though by-passing more recent and no less fundamental works on the subject by Keith Dowding and others). They harness these classics to provide us with a set of lenses to see and problematize power at work in 'collaborative', 'win-win', 'bottom-up', and 'horizontal' processes.

This chapter sets the tone for the thematic chapters to follow, i.e. on the measurement of interactive governance, on the complex combinations of vertical, horizontal, and diagonal arrangements it might entail, on the question of how such emergent processes might be institutionalized and indeed how they themselves can be 'governed'. Throughout these chapters the authors draw upon yet tailor to their analytical purposes existing scholarship to develop pertinent empirical frameworks and ask penetrating normative questions.

The chapter on how interactive governance itself can be governed is one of the most innovative features of the book. It develops a theory of metagovernance (or 'reflexive, higher order governance practices', p. 131). This theory carves out a series of key metagovernance functions and mechanisms somewhat similar to those discerned previously in Dutch and American studies of network management. This theoretical chapter brings to the fore the really pivotal questions of 'what role for the state?', 'what role for politics?', and 'what role for the politician?' in interactive governance.

These questions have been the elephant in the room in too much previous writing on governance, networks, and partnerships. One of the great accomplishments of this book is that it tackles these questions head on - not solving them but providing a language for doing so and offering a thoughtful set of alternatives and arguments for and against various roles and styles of political steering of interactive governance. The account once again clarifies that politicians and political institutions everywhere are facing a great challenge to not just their traditional modus operandi but to their very relevance, authority, and legitimacy. They must come to terms with a swathe of governance arrangements that are often not of their making, which they cannot control by top-down interventions. And yet these arrangements are often felt to be at least as effective and 'democratic' as traditional scripts of democratic authorization and accountability and conventional forms of state-centric, top-down public problem solving.

Throughout most of the study, the authors are consistently analytical in their approach, though in its final chapters they begin to show their colours a bit more. They turn their enterprise more explicitly towards prescriptions for making interactive governance work 
effectively and improving its democratic quality. But even in those chapters, they offer a nuanced argument as well as tools for evaluation. Their work allows even-handed judgments and retains a key awareness of the complexities, trade-offs, and potential negative side-effects of what seems to be the new frontier in the way in which modern societies govern themselves.

Paul 't Hart

Utrecht University and Netherlands School of Public Administration 